\title{
Characteristics Analysis of the Archimedes Screw Turbine Micro-hydro Power Plant with Variation of Turbine Elevation Angle
}

\author{
Bachtera Indarto, Afif Mahrus Kurnia Putra, and Muhammad Arief Bustomi* \\ Department of Physics, Institut Teknologi Sepuluh Nopember (ITS), Surabaya 60111, Indonesia
}

\begin{abstract}
Electrical energy has become a basic need of modern society, but the supply of electricity has not yet fully met the needs of the community. Many potential energy sources can be converted into electrical energy. One potential of energy sources is water flow which can be used for micro-hydro power plants in remote areas. This study aims to analyze the characteristics of the Archimedes screw turbine of micro-hydro power plant, in particular concerning on variations in the elevation angle of the turbine. Characteristics determination was carried out on a prototype of a micro-hydro power plant using a Brush Less Direct Current (BLDC) generator and two blades of Archimedes screw turbine. The varied turbine elevation-angle was applied, namely 20, 25, 30, 35 , and $40^{\circ}$, with a water discharge of $2.64 \mathrm{~L} / \mathrm{s}$. The results show that an increase in the turbine elevation angle from 20 to $40^{\circ}$ causes an enhancement in mechanical characteristics, i.e. torque and rpm, as well as electrical characteristics, i.e. voltage, current, and electric power. The mechanical and electrical characteristics reach a maximum value at the elevation angle of about $30^{\circ}$, which is $27.87 \mathrm{~mW}$ at $1 \mathrm{k} \Omega$ load. Furthermore, increasing the elevation angle to become more than $30^{\circ}$ causes a decrease in mechanical and electrical characteristics.
\end{abstract}

Keywords: Power plant; Micro-hydro; Archimedes screw turbine; Elevation angle

*Corresponding author: a_bustomi@physics.its.ac.id

Article history: Received 27 Maret 2021, Accepted 29 Juni 2021, Published June 2021.

http://dx.doi.org/10.12962/j24604682.v17i2.8983

2460-4682 (c)Departemen Fisika, FSAD-ITS

\section{INTRODUCTION}

Electrical energy is a basic requirement for modern society. Every year there is an increase in the community's need for electrical energy. In many countries, the management of electrical energy has been carried out well. This management includes the generation, distribution, and marketing of electrical energy to the public [1]. Regarding the distribution of electrical energy, not all areas can be reached by the electricity network. These areas are usually remote areas that are difficult to be reached by the electricity grid. Even though some remote areas have several potential sources of energy that can be converted into electrical energy. One example of a potential source of energy is a river flow that passes through this remote area.

Micro-hydro power from rivers can be a solution for supplying electrical energy in remote areas [2]. There are various types of micro-hydro power plants with their respective advantages and disadvantages [3-5]. One type of micro-hydro power plant is the Archimedes screw turbine power plant. The Archimedes screw turbine micro-hydro plant has several advantages, namely that it can be used on river currents that are not too swift [6], does not damage the environment around the river [7], does not interfere with fish life in the river [8], and others. Archimedes screw turbine micro-hydro plant has been widely researched and studied, both theoretically [9] and experimentally [10]. The results of these studies have shown that the Archimedes screw turbine has a fairly good performance.

Several researchers have conducted analysis and design of Archimedes screw turbines to obtain optimal turbine performance $[11,12]$. The utilization of river flow as a source of electrical energy can also be combined with the use of solar energy to obtain a more adequate supply of electrical energy for remote areas [13]. Several studies on the characteristics of Archimedes screw turbines on various factors have also been carried out. Some examples are the effects of the level of filling water (fluid) [14], the flow of water (fluid) passing through the turbine [15], and the slope and the number of turbine blades [16] on the characteristics and performance of the turbine.

This paper discusses the effect of the turbine elevation an;e on the characteristics and performance of Archimedes screw turbine micro-hydro generators. The results of this study complement various results that have been reported in previous studies. The novelty and uniqueness of this research is that the turbine and generator are analyzed as a single system. As a single combined turbine and generator system, there will be two kinds of system characteristics, namely mechanical and electrical characteristics. Here, the mechanical characteristics of torque and $\mathrm{rpm}$ at various turbine elevation angles are discussed, as well as the electrical characteristics of the voltage and current to obtain the generator power at various elevation angles of the turbine. 


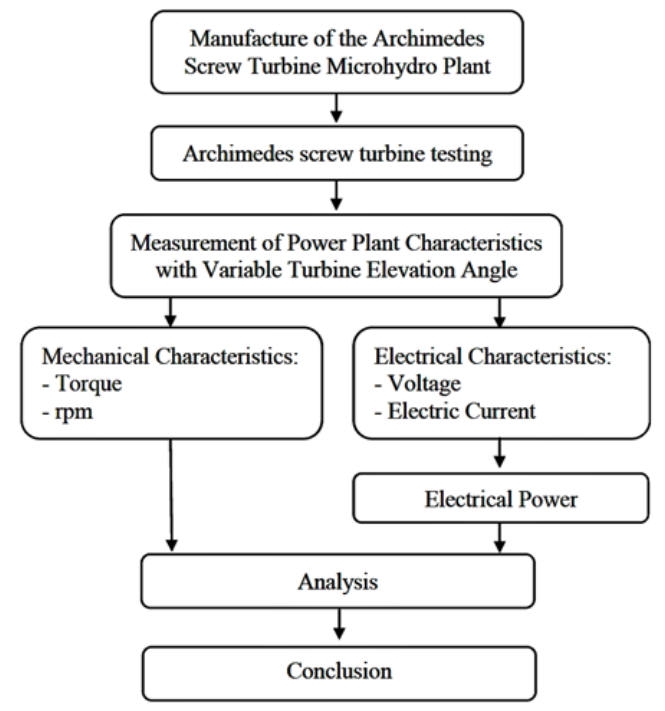

FIG. 1: The flowchart of the research

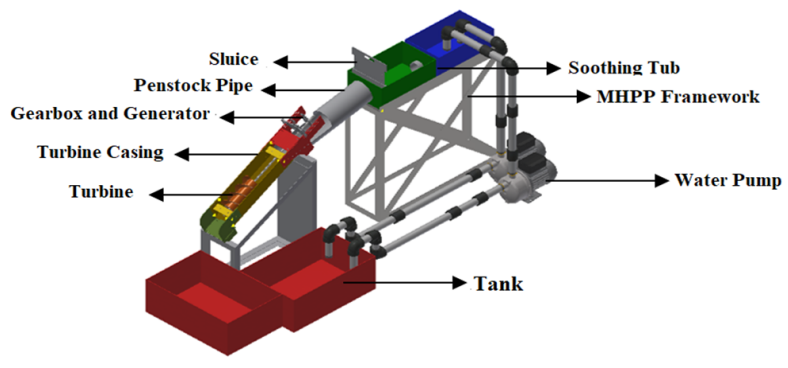

FIG. 2: The design of Archimedes screw turbine micro-hydro plant

\section{METHOD}

In general, the method applied in the research are stated in the flowchart shown in Fig. 1.

\section{A. Tools and Materials}

The tools and materials used in the research were Archimedes screw turbines, PVC pipes, tranquilizer tanks, reservoirs, generators, and water pumps, which has a function as a generator driving turbine, as a supply pipe for water stock into the tub, to calm the water flow, to accommodate the flow of water, to convert water flow energy into electrical energy, and as a source of water flow, respectively.

\section{B. The Design of Archimedes Screw Turbine Micro-hydro Plant}

The design of the Archimedes screw turbine micro-hydro power plant is shown in Fig. 2.

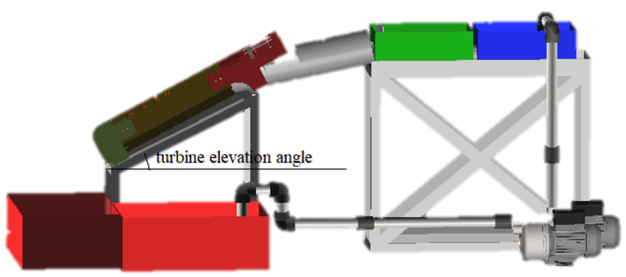

FIG. 3: Illustration of the turbine elevation angle

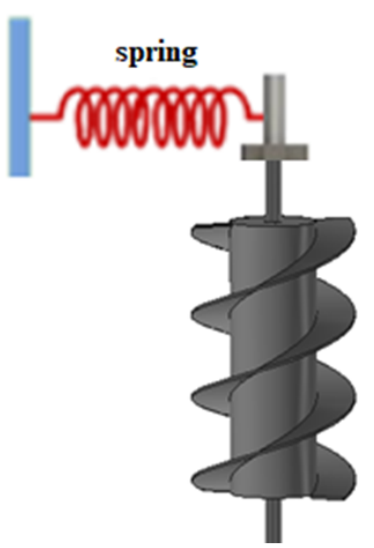

FIG. 4: The scheme of the torque measurement of turbine, consisting of a spring that is attached to the turbine shaft through a rope

\section{Characteristics Measurement}

The measurement of the mechanical and electrical characteristics of the Archimedes screw turbine micro-hydro generator was carried out at various variations of the turbine elevation angle. In this study, five variations of the turbine elevation angle were employed, namely $20,25,30,35$, and $40^{\circ}$. The turbine elevation-angle parameters are illustrated in Fig. 3. The water flow was fixed at $2.64 \mathrm{~L} / \mathrm{s}$, and the gearbox was at the ratio of $2.5: 1$. The measurement of mechanical characteristics consisted of measuring the torque and rpm produced by the turbine. The electrical characteristics was evaluated by measuring the voltage and electric current generated by the generator. Lastly, the generator power was calculated based on the measurement results of voltage and electric current.

\section{Torque Measurement}

The torque measurement of the turbine was performed by using a spring that is attached to the turbine shaft through a rope. Springs and ropes will act as brakes on the turbine shaft. The turbine rotation will be weaken and stopped after a while due to braking by the elongation force of the spring. Fig. 4 shows the torque measurement scheme for the turbine. The amount of torque from the turbine is equal to the torque by 


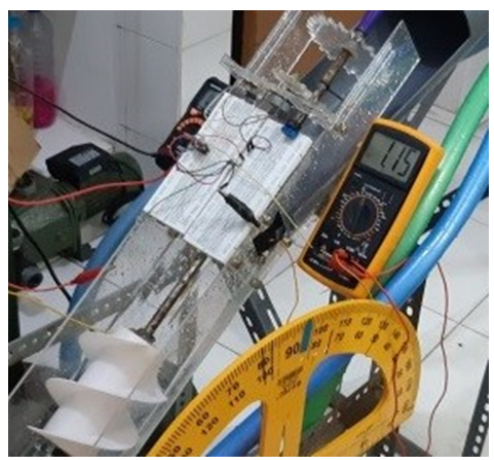

FIG. 5: Measurement of the generator's voltage and current using using a digital multimeter

the spring force as indicated in Eq. (1) [8]

$$
\tau=-k \Delta x r
$$

where $\tau$ is the torque on the turbine, $k$ is the spring constant, $\Delta x$ is the extension on the spring, and $r$ is the distance from the braking surface to the center of the turbine shaft.

\section{RPM Measurement}

The rpm measurement on the turbine was carried out by counting the number of revolutions in a certain time interval. In this study, the used time interval was 60 seconds, thus the rpm is calculated following Eq. (2).

$$
\text { rpm }=\frac{n}{t} \cdot 60
$$

Here, rpm describes the number of turbine rotations in one minute, $n$ is the number of turbine rotations, and $t$ is the time interval of turbine rotation in minutes.

\section{Measurement of Voltage and Current}

The measurement of voltage and current was conducted by connecting the output of an AC generator to a series of diodes and capacitors to become a DC electricity. The DC electricity was connected and measured using a digital multimeter. The measurements of electric voltage were done at various variations of the turbine elevation angle, and that of electric current was carried out using 5 variations of the resistor loading at varied turbine elevation-angle. Fig. 5 presents a photo of the generator's voltage and current measurement using a digital multimeter.

\section{Calculation of Electrical Power}

The electrical power generated by the generator was calculated from the measured voltage and currents which were

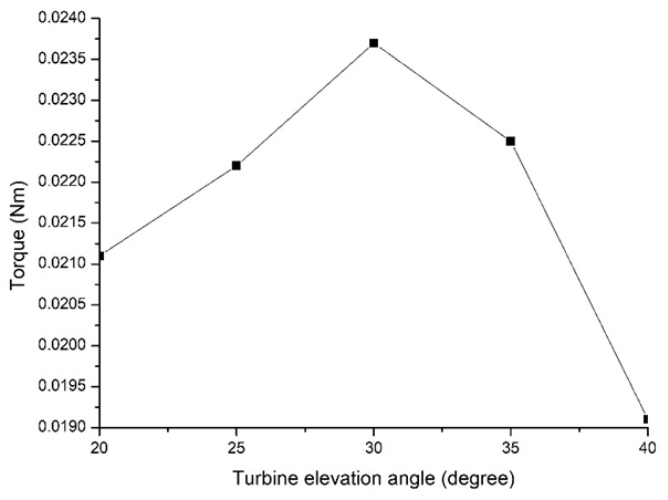

FIG. 6: The graph of obtained torque vs. turbine elevation angle

obtained at 5 variations of the resistor loading. Electric power was calculated following Eq. 3 [9]

$$
P=V \cdot I
$$

where $P, V$, and $I$ describe the electrical power, voltage and currents, respectively.

\section{RESULTS AND DISCUSSION}

\section{A. Torque Measurement Results}

The torque measurement was carried out using a spring with the spring constant of $28.245 \mathrm{~N} / \mathrm{m}$ on a turbine with a shaft radius of $6 \mathrm{~mm}$. The torque at various turbine elevationangles was calculated using Eq. (1). The calculated torque are presented in the graph of torque vs. turbine elevation angle shown in Fig. 6.

It can be seen from Fig. 6 that when the turbine elevation angle increases from 20 to $30^{\circ}$, the produced torque increases as the angle increases. This is because the greater the elevation angle, the greater the difference in height between the two ends of the turbine. Furthermore, increasing the height difference will cause an increase in the amount of hydrostatic force, thus increasing the torque in the turbine. However, at the angle variation from 30 to $40^{\circ}$ the opposite tendency happens. The greater the turbine elevation angle, the smaller the torque generated. This can be understood as the higher the elevation angle will cause the water flow to get closer to one point on the blade so that only part of the water hits the turbine and causes a decrease in the torque of the turbine.

\section{B. Results of RPM Measurement}

The results of the rpm measurement are presented in the graph of turbine rpm vs. turbine elevation angle indicated in Fig. 7.

An increase in the turbine elevation angle from 20 to $30^{\circ}$ causes an enhancement in the turbine rpm, while that from 30 


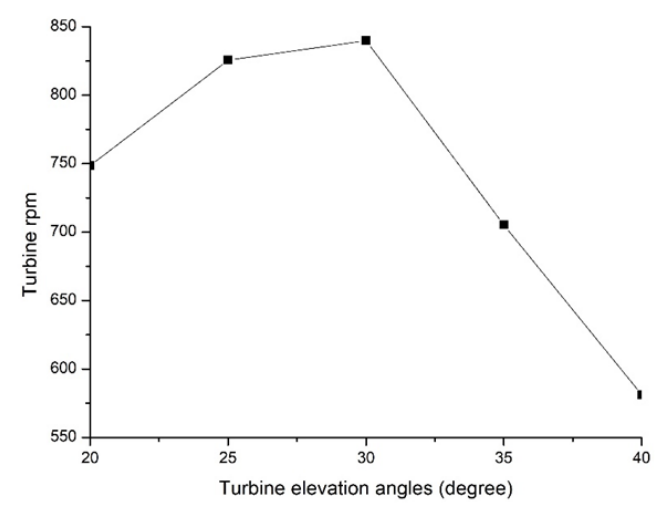

FIG. 7: The graph of turbine rpm vs. turbine elevation angle

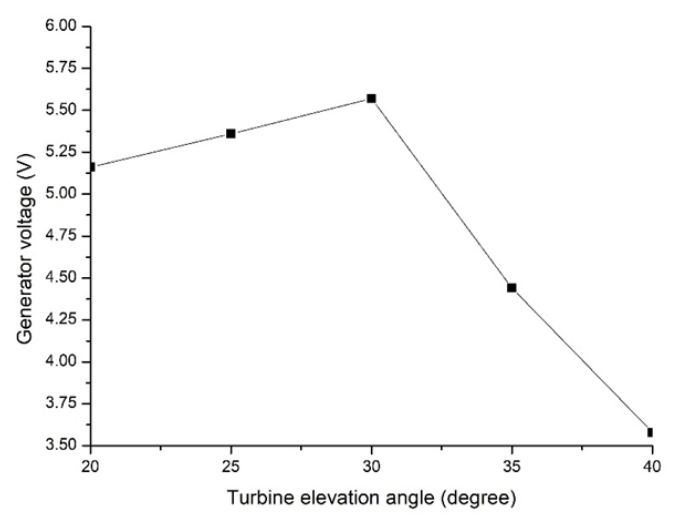

FIG. 8: The graph of generator voltage vs. turbine elevation angle

to $40^{\circ}$ give rise to a decrease in the turbine rpm. The changes pattern of the turbine rpm to the elevation angle is indeed the same with that of the obtained torque as both quantities are proportional to each other.

\section{Voltage and Electric Current}

The results of electric voltage of the generator measured without loading are presented in Fig. 8, showing the graph of generator voltage vs. turbine elevation angle.

As the changes of the obtained torque and turbine rpm, the generator voltage also increases with increasing the turbine elevation angle from 20 to $30^{\circ}$, which then decreases at the angle of $30-40^{\circ}$. The generator voltage changes proportionally to the turbine rpm over the elevation angle. Moreover, the electric current and voltage measurements were also conducted at various variations of resistor loading, namely $1 \mathrm{k} \Omega$, $2 \mathrm{k} \Omega, 3 \mathrm{k} \Omega, 4 \mathrm{k} \Omega$, and $5 \mathrm{k} \Omega$. The results are summarized in Table 1.

Fig. 9 is an example of the generator loading curves at the turbine elevation angle of $30^{\circ}$. It can be seen that the increase in the value of the resistor loading causes a decrease in the electric current and a slight increase in the electric voltage.
TABLE I: The results of measuring electric currents and voltages at the varied resistor loading and elevation angles

\begin{tabular}{lllllllllllll}
\hline Angle & \multicolumn{9}{c}{ Currents $(\mathrm{mA})$} \\
\cline { 2 - 12 } & $1 \mathrm{k} \Omega$ & $2 \mathrm{k} \Omega$ & $3 \mathrm{k} \Omega$ & $4 \mathrm{k} \Omega$ & $5 \mathrm{~K} \Omega$ & $1 \mathrm{k} \Omega$ & $2 \mathrm{k} \Omega$ & $3 \mathrm{k} \Omega$ & $4 \mathrm{k} \Omega$ & $5 \mathrm{k} \Omega$ \\
\hline $20^{\circ}$ & 4.77 & 2.41 & 1.64 & 1.26 & 1.03 & 4.66 & 4.71 & 4.82 & 4.95 & 5.08 \\
$25^{\circ}$ & 4.65 & 2.40 & 1.63 & 1.27 & 1.03 & 4.56 & 4.58 & 4.62 & 4.64 & 4.74 \\
$30^{\circ}$ & 5.34 & 2.71 & 1.85 & 1.41 & 1.16 & 5.22 & 5.29 & 5.34 & 5.39 & 5.44 \\
$35^{\circ}$ & 4.02 & 2.08 & 1.45 & 1.45 & 0.93 & 3.93 & 3.96 & 4.03 & 4.05 & 4.09 \\
$40^{\circ}$ & 3.09 & 1.52 & 1.11 & 0.77 & 0.71 & 2.74 & 2.97 & 3.00 & 3.10 & 3.24 \\
\hline
\end{tabular}

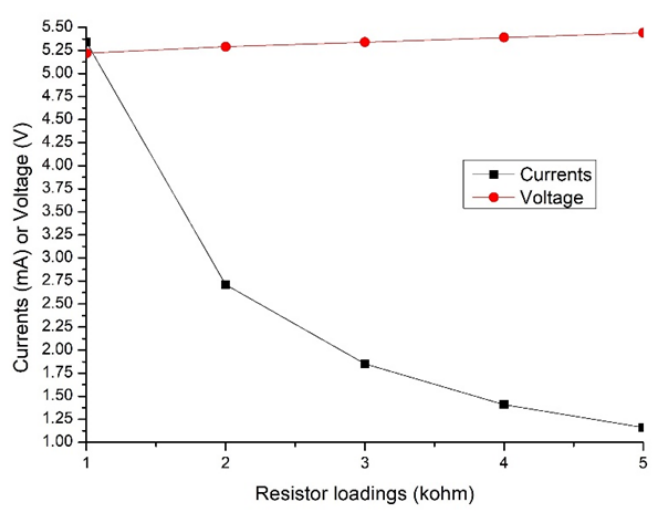

FIG. 9: The graph of the generator loading at the turbine elevation angle of $30^{\circ}$

From the data in Fig. 9, the amount of electric power for each generator loading value can be calculated. At 1, 2, 3, 4, and $5 \mathrm{k} \Omega$ load, the electrical power obtained is $27.87,14.37$, $9.92,7.65$, and $6.32 \mathrm{~mW}$, respectively. The greater the value of the resistor loading on the generator, the lower the electric power. This is caused by the fact that with the addition of the resistor loading value a decrease in the electric current is more appreciable than an increase in the voltage.

\section{Electrical power}

The amount of electrical power generated by the generator is calculated from the measured voltage and electric current using Eq. (3). The generator power was calculated on various resistor loading variations: $1,2,3,4$, and $5 \mathrm{k} \Omega$. At each resistor loading, the electric power was calculated for each turbine elevation angle from $20,25,30,35$, and $40^{\circ}$. The results of the calculated electric power are presented in Table 2.

In Table 5, one can see that the greatest electric power occurs at the turbine elevation angle of $30^{\circ}$ and the resistor loading of $1 \mathrm{k} \Omega$ with the power of $27.87 \mathrm{~mW}$. Table 5 also shows that the value of the loading also affect the amount of power generated by the generator.

\section{E. Discussion}

From the measurements results of mechanical characteristics (Fig. 6 and 7) and electrical characteristics (Fig. 8, Table 
TABLE II: The calculation results of the electrical power at various resistor loading and elevation angles

\begin{tabular}{llllll}
\hline Angle & \multicolumn{5}{c}{ Power $(\mathrm{mW})$} \\
\cline { 2 - 6 } & $1 \mathrm{k} \Omega$ & $2 \mathrm{k} \Omega$ & $3 \mathrm{k} \Omega$ & $4 \mathrm{k} \Omega$ & $5 \mathrm{k} \Omega$ \\
\hline $20^{\circ}$ & 22.27 & 11.34 & 7.94 & 6.28 & 5.28 \\
$25^{\circ}$ & 21.30 & 11.00 & 7.54 & 5.89 & 4.90 \\
$30^{\circ}$ & 27.87 & 14.37 & 9.91 & 7.65 & 6.32 \\
$35^{\circ}$ & 15.81 & 8.27 & 5.84 & 4.57 & 3.80 \\
$40^{\circ}$ & 8.51 & 4.54 & 3.35 & 2.41 & 2.29 \\
\hline
\end{tabular}

1, and Table 2) of the Archimedes screw turbine micro-hydro generator at various variations of the turbine elevation angle from 20 to $40^{\circ}$, it is known that the turbine elevation angle of $30^{\circ}$ produces maximum values of mechanical and electrical characteristic. The maximum torque, rpm, voltage, current, and electrical power are obtained at the elevation angle of $30^{\circ}$. Increasing the elevation angle of the turbine from 20 to $3030^{\circ}$ causes a significant increase in the hydro-static force that rotates the turbine, hence enhances the torque and rpm of the turbine rotation. The faster the turbine rotation results in an increase in the voltage, current, and electrical power that occurs in the generator. On the other hand, an increase in the elevation angle of the turbine from 30 to $4030^{\circ}$ influences the flow of water not entirely to the turbine, causing a decrease in the torque and rpm of turbine rotation. As the result it causes a decrease in voltage, current, and electrical power that occurs in the generator.

Regarding the turbine elevation angle that produces maximum characteristics, the results of this study can be compared with the theoretical results of Muller and Senior's research. Muller and Senior have formulated a simple theory that can be used to calculate the effect of the number of blades on turbine efficiency. The results of Muller and Senior's study show that the increase in the number of turbine blades can improve turbine efficiency [9]. Ten years later, Delinger et. al. experimented to measure the effect of the number of turbine blades on the efficiency of Archimedes screw turbines. Delinger et. al. examined the relationship between the number of turbine blades and the turbine elevation angle which resulted in maximum characteristics. The results of Dellingers research show that the use of more blades can reduce the elevation angle of the turbine which results in maximum characteristics. This is because increasing the number of blades in the turbine will maximize the flow of water hitting the turbine [16]. Next, Rorres made an optimal design of the Archimedes screw turbine micro-hydro generator by including the number of turbine blades as one of the parameters for optimizing the generator characteristics [12]. The results obtained from this study are still limited to the elevation angle range from 20 to $40^{\circ}$ and the elevation angle changes of $5^{\circ}$ according to the measurement scheme (Figs. 6, 7, 8, Table 1 and 2). To obtain a more complete measurement of the mechanical and electrical characteristics of the screw turbine micro-hydro generator, further research is required to be carried out at various angle ranges outside the range of 20 to $40^{\circ}$. Likewise, to obtain a more detailed measurement of the mechanical and electrical characteristics of the screw turbine micro-hydro generator, then it is necessary to do further research on the turbine elevation angle range from 20 to $40^{\circ}$ with a change in the elevation angle of less than $5^{\circ}$.

\section{SUMMARY}

The results of the study showed that the maximum mechanical characteristics, namely torque and maximum rpm, occurred at an elevation angle of $30^{\circ}$ with a torque of about $0.0237 \mathrm{Nm}$ and a large turbine rpm of about $839.85 \mathrm{rpm}$. The maximum electrical characteristics, namely the maximum voltage, current, and power, also occur at the angle of $30^{\circ}$ with an appreciable voltage of $5.44 \mathrm{~V}$, a current of $5.34 \mathrm{~mA}$, which then results in the electrical power of $27,873 \mathrm{~mW}$. These maximum values is obtained at a $1 \mathrm{k} \Omega$ load. Increasing the elevation angle of the turbine from 20 to $30^{\circ}$ causes a significant increase in the hydro-static force that rotates the turbine. On the other hand, an increase in the elevation angle of the turbine from 30 to $40^{\circ}$ affects the flow of water not entirely to the turbine.

\section{Acknowledgment}

The authors would like to thank the Department of Physics, Faculty of Science and Data Analysis, Institut Teknologi Sepuluh Nopember (ITS) Surabaya for the support of research facilities so that this research can be carried out well.
[1] B. Bakhtyar et al., Renewable energy in five southeast Asian countries: Review on electricity consumption and economic growth, Renewable and Sustainable Energy Reviews, vol. 26, pp. 506-514, 2013.

[2] A. H. Elbatran et al., Operation performance and economic analysis of low head micro-hydropower turbines for rural and remote areas: A review, Renewable and Sustainable Energy Reviews, vol. 43, pp. 40-50, 2015.

[3] L. Barelli et al., Mini-hydro: A design approach in case of torrential rivers, Energy, vol. 58, pp. 695-706, 2013.

[4] D. K. Okot, Review of small hydropower technology, Renew- able and Sustainable Energy Reviews, vol. 26, pp. 515-520, 2013.

[5] G. Ardizzon, G. Cavazzini, and G. Pavesi, A new generation of small hydro and pumped-hydro power plants: Advances and future challenges, Renewable and Sustainable Energy Reviews, vol. 31, pp. 746-761, 2014.

[6] D. Zhou and Z. (D.) Deng, Ultra-low-head hydroelectric technology: A review, Renewable and Sustainable Energy Reviews, vol. 78, pp. 23-30, 2017.

[7] A. Kozyn, S. Ash, and W. Lubitz, Assessment of Archimedes screw power generation potential in Ontario, in Proceedings 
Climate Change Technology Conference (CCTC) 2015, Montreal, Canada, 2015, Paper Number 1570095585.

[8] A. T. Piper et al., The impact of an Archimedes screw hydropower turbine on fish migration in a lowland river, Ecological Engineering, vol. 118, pp. 31-42, 2018.

[9] G. Muller and J. Senior, Simplified Theory of Archimedean Screws, J. Hydraulic Research, vol. 47 (5), pp. 666-669, 2009.

[10] J. Rohmer et al., Modeling and experimental results of an Archimedes screw turbine. Renewable Energy, vol. 94, pp. 136146, 2016.

[11] Z. A. Kraybill, Structural Analysis of an Analysis of an Archimedes Screw and a Kinetic Hydro Turbine, Thesis, Lehigh University, Pennsylvania, USA, 2013.

[12] C. Rorres, The Turn of the Screw: Optimal Design of an Archimedes Screw, J. Hydraulic Eng., vol. 126 (1), pp. 72-80,
January 2000.

[13] K. Shahverdi et al., Energy harvesting using solar ORC system and Archimedes Screw Turbine (AST) combination with different refrigerant working fluids, Energy Conversion and Management, vol. 187, pp. 205-220, 2019.

[14] W. D. Lubitz, M. Lyons, and S. Simmons, Performance model of Archimedes screw hydro turbines with variable fill level, J. Hydraulic Eng., vol. 140 (10): 04014050, 2014.

[15] T. Saroinsong et al., Fluid Flow Phenomenon in a Three-Bladed Power-Generating Archimedes Screw Turbine, J. Eng. Sci. and Tech. Review, vol. 9 (2), pp. 72-79, 2016.

[16] G. Dellinger et al., Effect of slope and number of blades on Archimedes screw generator power output, Renewable Energy, vol. 136, pp. 896-908, 2019. 